\section{Trabeculectomy with or without mitomycin-C for paediatric glaucoma in aphakia and pseudophakia following congenital cataract surgery}

AK Mandal' ${ }^{1}$ H Bagga'1, R Nutheti²,

VK Gothwal ${ }^{3}$ and AK Nanda'

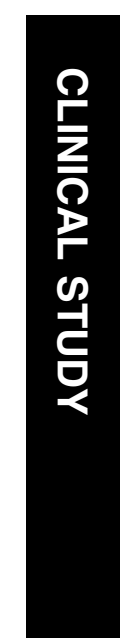

postoperative level of $18.4 \pm \mathbf{1 2 . 2} \mathbf{m m H g}$ (range: 2-60) with a mean follow-up of $24.2 \pm 17.9$ months. The mean reduction in IOP in the MMC group was $15.5 \pm 17.3$ and $16.3 \pm 13.8 \mathrm{mmHg}$ in the other group $(P=0.967)$. Overall, complete success was achieved in $36.8 \%$, qualified success in $21.1 \%$ and surgical failure in $42.1 \%$ of patients with a mean follow-up of $24.2 \pm 17.9$ months. There was no difference in the success between the two groups at the last follow-up. One patient developed bleb-related endophthalmitis in both eyes following trabeculectomy with MMC.

Conclusions The success rate of trabeculectomy in glaucoma following congenital cataract surgery was $36.8 \%$ at the end of 3 years. The present study proves a poor success rate of trabeculectomy in a small series of aphakic Asian Indian patients even with the use of MMC.

Eye (2003) 17, 53-62. doi:10.1038/

sj.eye. 6700180 antiglaucoma surgery and without any sightthreatening complication.

Results The mean age of patients was $8.8 \pm 5.5$ years at the time of trabeculectomy with MMC compared to $11.0 \pm 12.4$ years for trabeculectomy without MMC. Eight patients underwent trabeculectomy with MMC and 11 patients underwent trabeculectomy without MMC. There was no statistically significant difference between the two groups in terms of visual acuity, IOP, antiglaucoma medications, age at cataract surgery and at trabeculectomy. The IOP reduced from a preoperative level of $34.2 \pm 8.9 \mathrm{mmHg}$ (range: $20-52$ ) to a

\section{Introduction}

Glaucoma in aphakia and pseudophakia is one of the most common complications of congenital cataract surgery. ${ }^{1}$ The incidence of such glaucoma as reported in the early literature ranges from 0.9 to $14 \% .^{2}$ The incidence in more recent literature ranges from 6 to $24 \%$, depending on the series. ${ }^{3-8}$ While medical treatment should be tried first to lower the intraocular pressure (IOP), surgical procedure is often required to adequately control it.,
'Jasti V Ramanamma Children's Eye Care Centre LV Prasad Eye Institute Hyderabad, India

${ }^{2}$ International Centre for Advancement of Rural Eye Care, India

${ }^{3}$ Meera \& LB Deshpande Centre for Sight

Enhancement India

Correspondence: AK Mandal, Jasti V Ramanamma Children's Eye Care Centre

LV Prasad Eye Institute LV Prasad Marg Banjara Hills, Hyderabad 500034 India Tel: +91403548267 Fax: +9140354 8271 E-mail: mandal@ Ivpeye.stph.net

Presented in part as a poster at the annual meeting of the American Academy of Ophthalmology, New Orleans, Louisiana, November 1998. 
Standard glaucoma filtering surgery (trabeculectomy) has its own limitations with a poor success rate in the younger age group..$^{9-11}$ The barriers to success of filtering surgery in children and younger individuals include a thick and active Tenon's capsule and rapid wound healing response. ${ }^{12}$ Recently, intraoperative mitomycin-C (MMC) has been shown to be an effective adjunct chemotherapy with trabeculectomy including glaucoma following congenital cataract surgery. ${ }^{13-22}$ However, with the exception of the study by Walton, ${ }^{22}$ other reports have presented results of different procedures in all childhood glaucomas grouped together. ${ }^{17-21}$ AzuaraBlanco et al ${ }^{18}$ had limited success in aphakic childhood glaucoma. In their study, the probability of having IOP $<21 \mathrm{mmHg}$ with no antiglaucoma medication and with clinically stable glaucoma 1 year after trabeculectomy with MMC was $0 \%$ in the aphakic eyes $(n=8) .{ }^{18}$ They commented that an alternative therapeutic approach to aphakic childhood glaucoma might be needed. In contrast, aphakic glaucoma patients did well after congenital cataract surgery with MMC trabeculectomy with success rates ranging from 62 to $82 \%$, depending on the other reported series. ${ }^{17,19-22}$ However, most of the series included only few patients with short or unknown follow-up.

The purpose of the present study is to provide additional information regarding the outcome of trabeculectomy with or without MMC in a homogenous series of patients with glaucoma in aphakia or pseudophakia following congenital cataract surgery and to identify the risk factors for failure of this procedure.

\section{Patients and methods}

A retrospective review of medical records identified all patients of glaucoma in aphakia and pseudophakia following congenital cataract surgery who subsequently underwent trabeculectomy with or without MMC (19 consecutive patients, 23 eyes) between January 1989 and April 2000 at LV Prasad Eye Institute. Patients were identified by searching our database for diagnostic codes and by reviewing the old charts. In four patients who underwent glaucoma surgery in both eyes, only the first operated eye was included in this study.

All patients underwent a complete ocular examination before and after surgery. The information obtained by a retrospective chart review included (1) patient demographics, (2) diagnosis of glaucoma, (3) age at cataract surgery, (4) preexisting ocular abnormalities, (5) type of cataract, (6) type of procedure or instrumentation, (7) interval between cataract surgery and development of glaucoma, (8) pre- and postoperative data including visual acuities, disc findings, IOPs, visual field changes and antiglaucoma medications, (9) exposure time and dose of MMC, (10) surgical procedure, and (11) significant complications. Informed consent was obtained from all patients/parents and Institutional Review Board approval for this study was obtained.

\section{Surgical technique}

All trabeculectomies were performed by one surgeon (AKM) and have been detailed previously. ${ }^{13,14}$ A limbusbased flap of conjunctiva and Tenon's capsule was created. After haemostasis of the episcleral blood vessels with wet-field cautery, a one-half thickness triangular scleral flap ( $4 \mathrm{~mm}$ base at the limbus) was outlined and dissected anteriorly without entry into the anterior chamber. A surgical sponge measuring $4 \times 4 \mathrm{~mm}^{2}$ was soaked in a solution of $0.4 \mathrm{mg} / \mathrm{ml} \mathrm{MMC}$ (mitomycin-C powder was reconstituted in sterile water to give the final concentration). The sponge was placed over the dissected bed; a superficial scleral flap and the conjunctiva-Tenon layer were then draped over the MMC-soaked sponge so that only those ocular tissues in contact with the sponge were directly exposed to MMC. After $3 \mathrm{~min}$, the sponge was removed and MMC was irrigated thoroughly with $20 \mathrm{ml}$ balanced salt solution (BSS). A $2 \mathrm{~mm} \times 1 \mathrm{~mm}$ deep trabecular block was removed, and a peripheral iridectomy was performed.

The scleral flap was closed with three interrupted (one at the apex and one on each side of the triangular scleral flap) 10-0 nylon sutures. The conjunctivo-Tenon layer was closed with 8-0 polyglactin (Vicryl) suture on a tapered needle (Ethicon, Somerville, NJ, USA). After the closure, the conjunctiva was shown to be watertight. A drop of antibiotic-corticosteroid preparation and cyclopentolate was instilled in the conjunctival sac, and a patch and shield were applied on the eye. In cases where MMC was not used, standard trabeculectomy was performed with a few modifications in the form of three loose sutures or a single apical suture for scleral flap closure, partial Tenonectomy and cautery around the margins of the internal osteum. There were no definite criteria for applying or not applying $\mathrm{MMC}$; however, the surgeon (AKM) stopped using MMC more recently.

The postoperative medical regimen initially included $0.1 \%$ betamethasone eye drops administered every $2 \mathrm{~h}$ and then tapered over a period of 6 weeks, depending on the degree of inflammation. Cyclopentolate $1 \%$ eye drops were given 3 times a day for the first 4 postoperative weeks. A topical antibiotic (0.3\% gentamycin) was also administered 4 times daily for 1 week after surgery.

All patients were seen on the first postoperative day and then at 1, 3, 6 weeks and at every 3 months thereafter. At each visit, slit-lamp biomicroscopy for chamber depth, corneal appearance, IOP, bleb 
appearance and fundus examination was carried out wherever possible. IOP was measured while the patient was awake and in the seated position using a Goldmann applanation tonometer whenever patient cooperation permitted. For patients who were unable to cooperate with an office exam, a Perkins hand-held applanation tonometer was used during examination under anaesthesia using 1\% halothane. Age-appropriate methods of visual acuity testing were used.

Surgical success and failure were defined before data analysis. A 'complete' success was defined as an IOP at the most recent follow-up visit that was in the range 6-21 $\mathrm{mmHg}$ without any glaucoma medications, without evidence of glaucoma progression, without requirement for further glaucoma surgery, and in the absence of visually devastating complications. A 'qualified' success was defined when the previous condition was achieved with single topical antiglaucoma medication. Failure was defined if any of the following were present:

(1) IOP $>21 \mathrm{mmHg}$ with two or more medications,

(2) additional antiglaucoma surgery required,

(3) hypotony maculopathy, or (4) any other sightthreatening complications like bleb-related infection (BRI) and endophthalmitis. For the purpose of this study, ocular hypotony was documented to be present when IOP was $<6 \mathrm{mmHGg}$ on two consecutive postoperative visits employed to indicate statistical significance. MannWhitney U test was used to compare the mean IOP between trabeculectomy with MMC and trabeculectomy without MMC groups. Kaplan-Meier survival analysis was used to determine the success probabilities at various postoperative intervals. Log-rank test was applied to test the equality of survival distribution between the two groups.

\section{Results}

In total, 23 eyes of 19 patients were included in this study. Patient demographics are summarized in Table 1. There were 10 males and 9 females in the group. All patients were of Asian origin. The mean age at the time of initial cataract surgery was $2.9 \pm 3.5$ years (range: $0.2-12$ years; median: 1 year). The information regarding the instrumentation or the type of surgical procedure for cataract extraction was not available to our patients. The man time interval between cataract surgery and diagnosis of glaucoma was $7.2 \pm 7.8$ years (range: $0-27$ years; median: 5.8 years). The mean age of the patients at the time of trabeculectomy without MMC was $11.0 \pm 12.4$ years (range: $0.3-37$ years) and was $8.8 \pm 5.5$ years (range: 2-18 years) in the group with MMC ( $P=0.649$, MannWhitney $U$ test). Nine eyes (eight patients) underwent trabeculectomy with MMC while 14 eyes (11 patients) underwent trabeculectomy without MMC. The mean follow-up was $24.2 \pm 17.9$ months.

Four patients underwent bilateral trabeculectomy with MMC, but in separate operative sessions; only the first eye operated upon was included for statistical analysis in this study. In all, 21 eyes were aphakic and two eyes were pseudophakic. The mean horizontal corneal diameter was $11.0 \pm 1.6 \mathrm{~mm}$. However, the corneal diameter was less than $10 \mathrm{~mm}$ in three eyes. Two eyes had Peter's anomaly. The mean number of prior surgical procedures was two. The mean number of antiglaucoma medications used before trabeculectomy was beta-blockers in $94.7 \%$, pilocarpine in $36.5 \%$, and tablet acetazolamide in $42.1 \%$.

The IOP was reduced from a preoperative level of $34.2 \pm 8.9 \mathrm{mmHg}$ (range: $20-52$ ) to a postoperative level of $18.4+12.2 \mathrm{mmHg}$ (range: $2-60$ ) with a mean follow-up of $24.2 \pm 17.9$ months. The mean reduction in IOP in the MMC group was $15.4 \pm 17.3$ and $16.3 \pm 13.8 \mathrm{mmHg}$ in the other group ( $P=0.967$, Mann-Whitney $U$ test).

Complete success was achieved in $36.8 \%$ patients with a mean follow-up of $24.2 \pm 17.9$ months (range: 1.6-54 months). The IOP was controlled with one antiglaucoma medication in $21.1 \%$ patients, which was considered as a qualified success. Surgical failure occurred in $42.1 \%$ of

Table 1 Patient demographics (23 eyes of 19 patients of glaucoma following congenital cataract surgery)

\begin{tabular}{lc}
\hline Demographics & $N o$. \\
\hline Age at presentation (years) & \\
Mean & 9.6 \\
Median & 6.5 \\
Range & $0.08-37$ \\
Race & Asian \\
Gender & \\
Male & 10 \\
Female & 9 \\
Lens status (no. of eyes) & \\
Aphakic & 21 \\
Pseudophakic & 2 \\
Mean interval between cataract surgery & $7.2 \pm 7.8$ \\
and diagnosis of glaucoma (years) & \\
Median & 5.8 \\
Range & $0-27$ \\
Mean age at trabeculectomy (years) & \\
Without MMC & $11 \pm 12.4$ \\
Range & $0.3-37$ \\
With MMC & $8.8 \pm 5.5$ \\
Range & $0.2-18$ \\
Mean preoperative IOP (mmHg) & $34.2 \pm 8.9$ \\
Range & $20-52$ \\
Mean postoperative IOP (mmHg) & $18.4 \pm 12.2$ \\
Range & $2-60$ \\
Mean follow-up (mmHg) & $24.2 \pm 17.9$ \\
\hline
\end{tabular}

$\mathrm{MMC}=$ mitomycin $-\mathrm{C}, \mathrm{IOP}=$ intraocular pressure . 
patients at a mean postoperative interval of $18.3 \pm 16.0$ months (range: $0.9-40.2$ months). The success probabilities ( \pm standard error) were $78 \pm 1 \%, 57 \pm 13 \%$ and $33 \pm 13 \%$ at 12,24 and 36 months, respectively. Figure 1 shows the Kaplan-Meier survival curve of overall success rate. Figure 2 shows the Kaplan-Meier survival curve of successful IOP control in trabeculectomy with and without MMC. There was no significant difference $(P=0.5135$, log-rank test) in the survival distributions of the two groups.

Preoperative visual acuities are listed in Table 2. The final postoperative visual acuity was the same as, or better than, the preoperative level in $76.5 \%$ of the eyes that were categorized as a success. Four eyes (23.5\%), which were categorized as failures, had a decrease in visual acuity. Of these, two eyes belonged to a single patient who developed bleb-related endophthalmitis. This was successfully treated but the patient

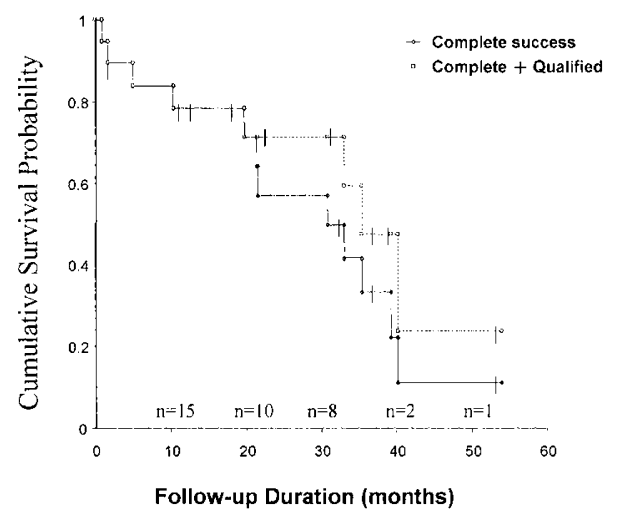

Figure 1 Kaplan-Meier survival plot showing overall success rate of modified trabeculectomy and trabeculectomy with MMC.

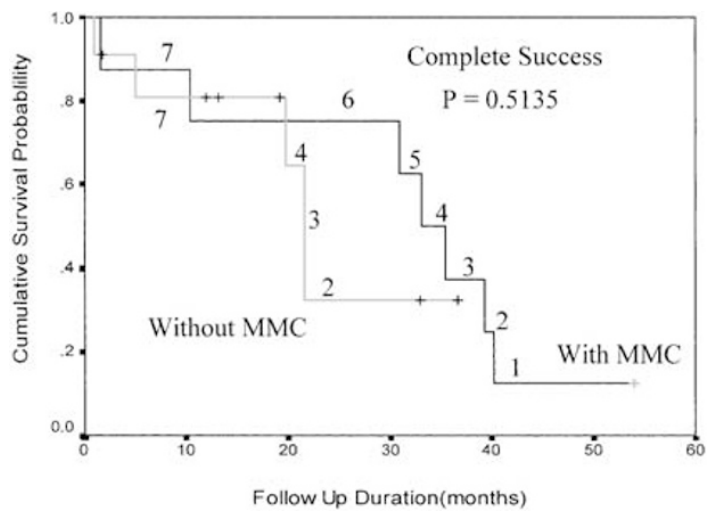

Figure 2 Kaplan-Meier life table estimation of successful intraocular pressure control following surgery. The outcome of modified trabeculectomy and trabeculectomy with MMC is compared.
Table 2 Preoperative visual acuities in 19 patients

\begin{tabular}{ll}
\hline Steady fixation and ability to follow light & $4(23.5 \%)$ \\
\hline$<20 / 400$ & $5(29.4 \%)$ \\
$>20 / 100-20 / 400$ & $5(29.4 \%)$ \\
$20 / 50-20 / 80$ & $2(11.8 \%)$ \\
$20 / 20-20 / 40$ & $1(5.9 \%)$ \\
\hline
\end{tabular}

subsequently developed chronic hypotony and choroidal detachment, which was not amenable to treatment, and the final visual acuity dropped from $20 / 50$ to $20 / 400$ in the left eye.

The blebs were characterized by their large, elevated, avascular and transparent appearance in patients who underwent trabeculectomy with MMC. In contrast, the blebs were diffuse and relatively thick-walled in patients who underwent trabeculectomy without MMC as seen in Figure 3.

There were no intraoperative complications. The postoperative complications in the two groups are listed in Table 3. Two patients developed dellen formation 6 weeks postoperatively, which was successfully treated with lubricant drops. Complete healing of the dellen occurred after treatment with topical lubricants. Figure 4 documents the anterior segment appearance in the right eye of the patient who developed bleb-related endophthalmitis. Figure 5 documents the appearance of the same eye after successful treatment of endophthalmitis. Similarly, Figures 6 and 7 document the appearance of the anterior segment when endophthalmitis developed in the left eye and outcome following treatment, respectively. Figures 8 and 9 document the 1 year and 14 months, respectively, of the postoperative appearance of the blebs of the right and

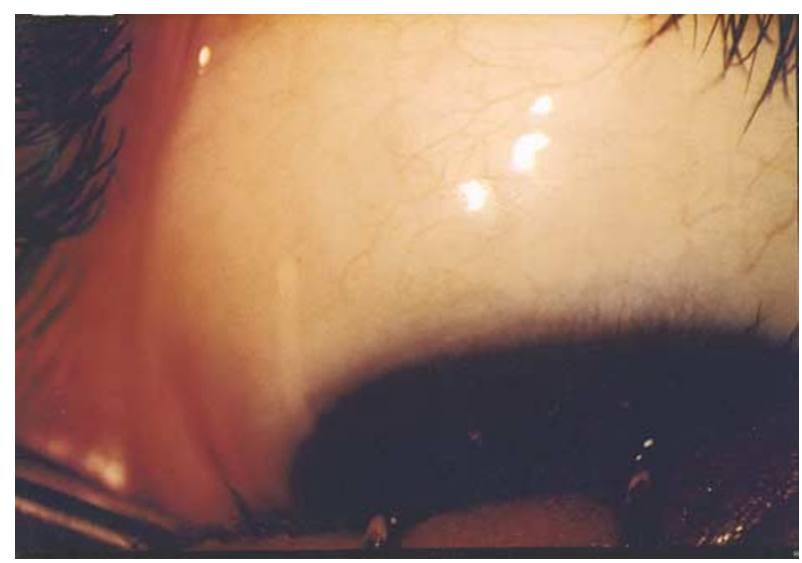

Figure 3 Diffuse and relatively thick-walled blebs with modified trabeculectomy. 
Table 3 Comparison of complications in trabeculectomy with MMC and modified trabeculectomy in glaucoma following congenital cataract surgery

\begin{tabular}{|c|c|c|}
\hline & $\begin{array}{c}\text { Trabeculectomy } \\
\text { with MMC } \\
\quad(n=9)\end{array}$ & $\begin{array}{c}\text { Trabeculectomy } \\
\text { without MMC } \\
\quad(n=14)\end{array}$ \\
\hline Endophthalmitis & 2 eyes $(22.2 \%)$ & - \\
\hline Choroidal detachment & 3 eyes $(33.3 \%)$ & 2 eyes $(14.3 \%)$ \\
\hline Hypotony maculopathy & 3 eyes $(33.3 \%)$ & - \\
\hline Encysted bleb & 1 eye $(11.1 \%)$ & - \\
\hline Shallow AC & - & 1 eye $(7.1 \%)$ \\
\hline Dellen & 2 eyes $(22.2 \%)$ & - \\
\hline SPK & 3 eyes $(33.3 \%)$ & - \\
\hline
\end{tabular}

$\mathrm{MMC}=$ mitomycin-C, $\mathrm{AC}=$ anterior chamber, $\mathrm{SPK}=$ superficial punctate keratitis.

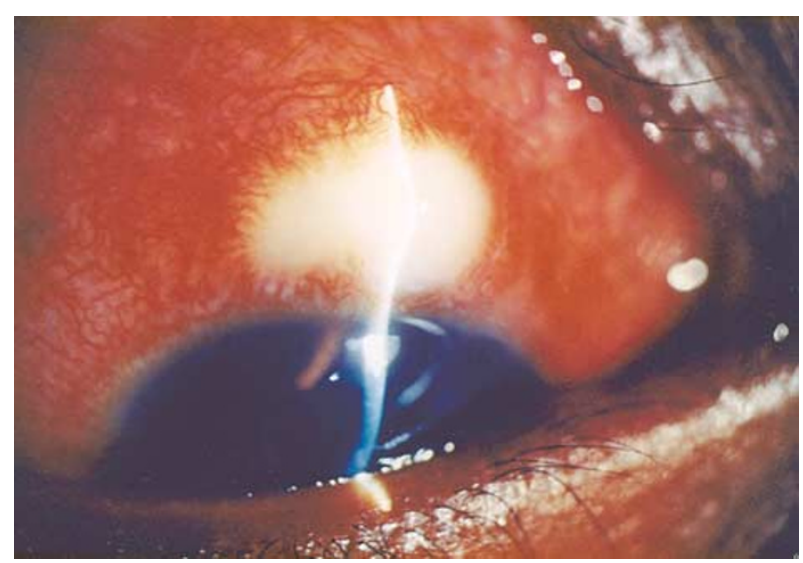

Figure 4 Anterior segment and bleb appearance of the right eye of the patient who developed bleb-related endophthalmitis 13 months following trabeculectomy with MMC.

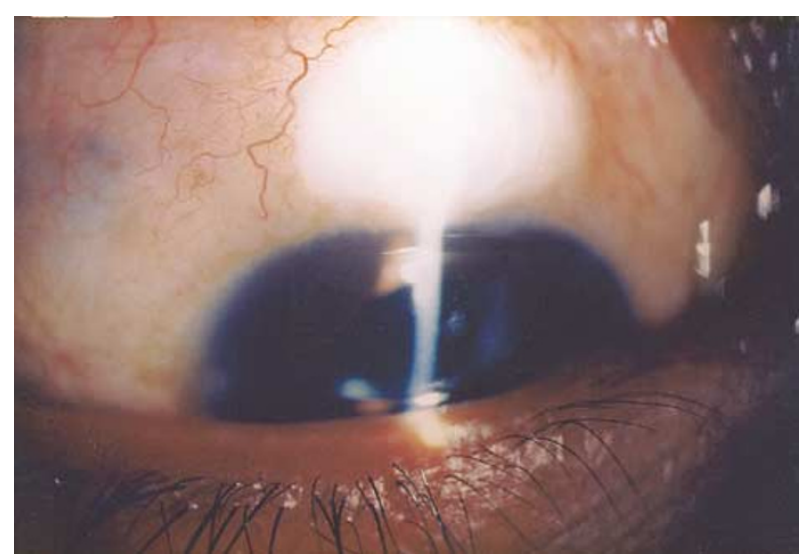

Figure 5 Appearance of the same eye after successful treatment of endophthalmitis.

left eye of the same patient who developed bleb-related endophthalmitis. Subsequently, the patient was seen with the diagnosis of chronic hypotony with thick

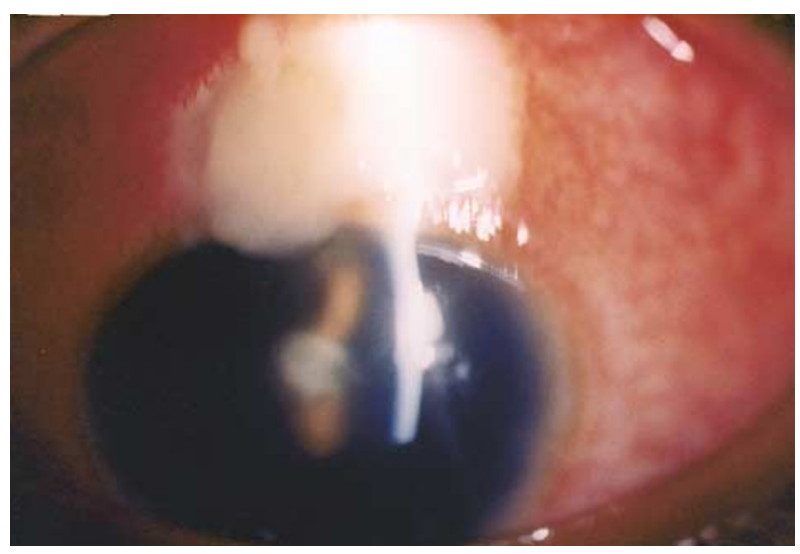

Figure 6 Anterior segment and bleb appearance of the left eye of the same patient who developed bleb-related endophthalmitis 1 year and 9 months following trabeculectomy with MMC.

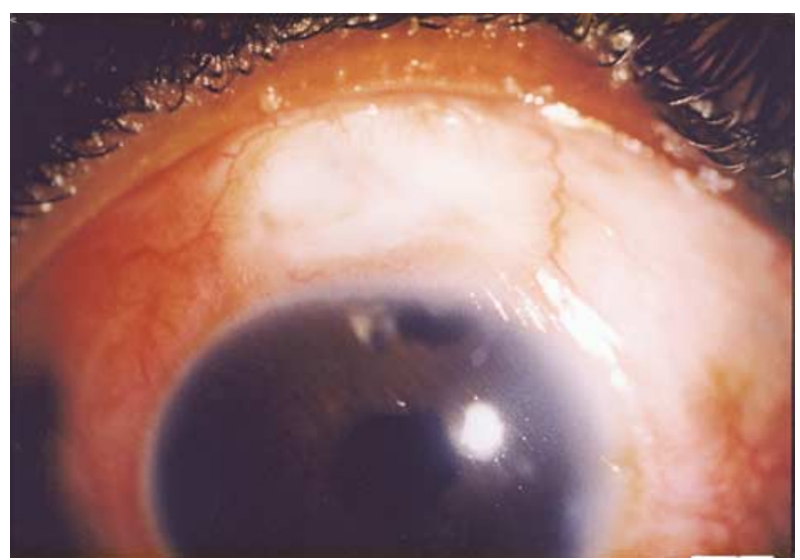

Figure 7 Appearance of the left eye of the patient who developed bleb-related endophthalmitis following treatment.

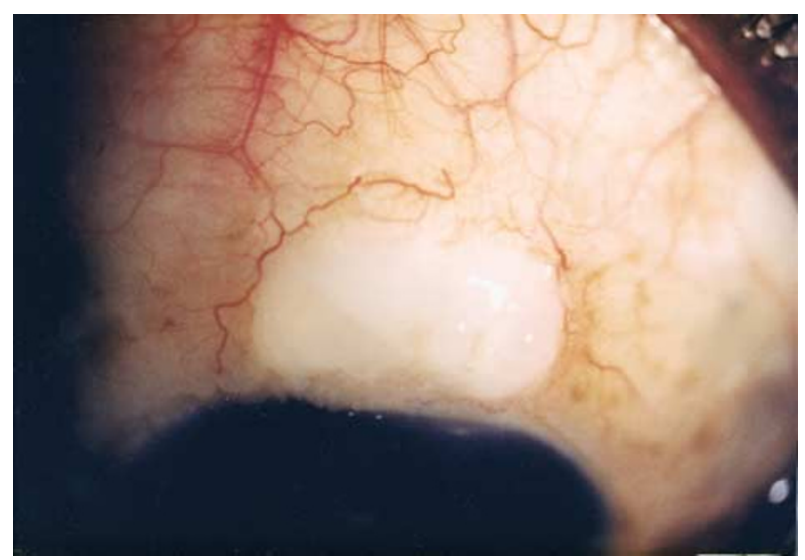

Figure 8 Appearance of the bleb of the right eye 1 year following treatment of endophthalmitis.

choroidals that did not respond to any therapy and visual acuity reduced from $20 / 50$ to $20 / 400$ in the left eye. 


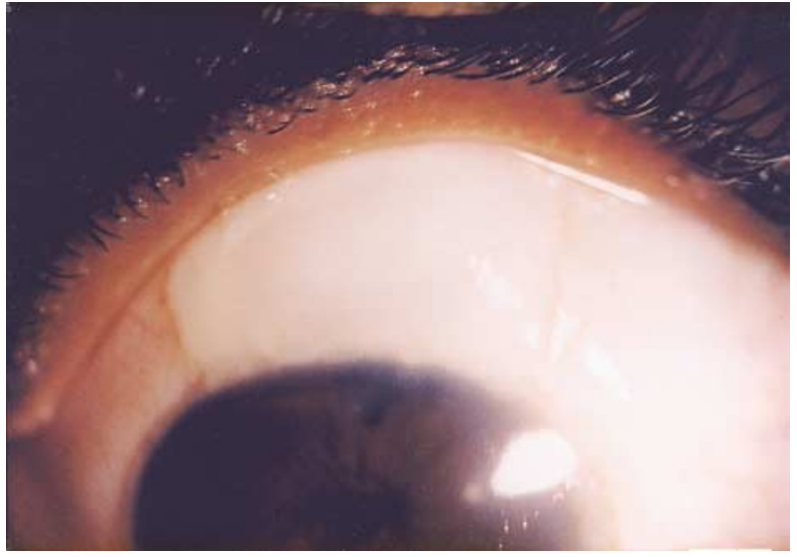

Figure 9 Appearance of the bleb of the left eye 14 months following treatment of endophthalmitis.

\section{Discussion}

Glaucoma in aphakia and pseudophakia is a wellrecognized sequelae of congenital cataract surgery, but there is still a lack of adequate information regarding its presentation, risk factors and management. Glaucoma may occur in either an acute form or chronic form. Acute glaucoma is typically of the angle closure type and usually presents in the early postoperative period. In contrast, open angle glaucoma (OAG) following congenital cataract surgery is not usually diagnosed until many years have passed. In our series, all the patients had open angles and the average time interval for the onset of glaucoma following congenital cataract surgery was $7.2 \pm 7.8$ years. This is in accordance with the existing knowledge in the literature. Simon $e t a l^{6}$ reported a mean time interval of 6.8 years. The average time interval between congenital cataract surgery and diagnosis of glaucoma was 12.2 years as reported by Asrani and Wilensky; ${ }^{3}$ while Phelps and Arafat; ${ }^{23}$ reported an interval ranging from 2 to 45 years. Asrani et $a l^{24}$ observed a decreased incidence of open angle glaucoma among eyes rendered primarily pseudophakic compared with those that remained aphakic after congenital cataract surgery. They reported a single case of openangle glaucoma found among 377 eyes with primary pseudophakia (mean age of patients: $5.1 \pm 4.7$ years; mean follow-up: $3.9 \pm 2.7$ years) following congenital cataract surgery. Extensive literature search has not revealed any reported case of OAG after primary IOL implantation of a congenital or developmental cataract in the absence of any other anterior segment anomalies. ${ }^{24}$ Interestingly, our series included two such cases and both eyes had pseudophakia with open angle gonioscopically. However, multiple surgeons were involved and various techniques of cataract surgery were employed, details of which were not known to us.
Glaucoma following congenital cataract surgery is refractory to surgical intervention for several reasons, including young age, history of prior surgery, associated subconjunctival scarring, aphakia and pseudophakia itself. Aphakia is also a known risk factor for failure in adult trabeculectomy surgery. ${ }^{25,26}$ Previous reports of outcome of filtering surgery without the use of any adjunctive antifibrotic agents in the management of a paediatric glaucoma have been disappointing. ${ }^{9-11}$ The use of antifibroproliferative agents such as 5-fluorouracil $(5-\mathrm{FU})^{27,28}$ and $\mathrm{MMC}^{29,30}$ which may improve the surgical prognosis, has been studied extensively in adults. Several prospective randomized studies in adults with high-risk glaucoma filtering surgery have shown that intraoperative MMC may be a better alternative to the use of postoperative 5-FU because MMC-augmented trabeculectomy is shown to have resulted in lower overall IOP, decreased dependence on postoperative antiglaucoma medication, and decreased corneal toxicity. ${ }^{31-33}$ Khaw et al, ${ }^{34}$ in an elegant study of cell culture analysis, demonstrated the greater effect of MMC as compared to 5-FU on both fibroblast proliferation and morphologic characteristics. Encouraging reports of intraoperative use of MMC in adults, ${ }^{31-33}$ coupled with the difficulties encountered by repeated injections of 5FU in children, prompted us to use MMC intraoperatively during glaucoma filtering surgery in these patients.

Mitomycin-C has emerged as an effective antimetabolite for topical use during trabeculectomy. It is an antineoplastic antibiotic isolated from the fermentation filtrate of Streptomyces caespitosus, which has the ability to suppress significantly fibrosis and vascular ingrowth after exposure to the filtration site. The time of application of MMC in our study was 2-3 min. After a mean follow-up of $24.2 \pm 17.9$ months, $36.8 \%$ of the eyes demonstrated successful control of IOP (IOP less than or equal to $21 \mathrm{mmHg}$ ). This suggests that glaucoma following congenital cataract surgery is refractory to filtering surgery even with the intraoperative use of MMC.

The probability of having IOP $<21 \mathrm{mmHg}$ with no antiglaucoma medication and with clinically stable glaucoma 1 year after surgery was $0 \%$ in the eight aphakic eyes in the study by Azuara-Blanco et al. ${ }^{18}$ The mean age at the time of surgery was 5.7 years in that study, while the mean age at surgery was $11.0 \pm 12.4$ years in trabeculectomy without MMC group and $8.5 \pm 5.5$ in the MMC group in our study. The relatively better success rate in our series could be related to the application time of MMC, which was $3 \mathrm{~min}$ compared to $2.2 \mathrm{~min}(0.9 \mathrm{~min}$ lower) in the study by Azaura-Blanco et al. 
Table 4 summarizes the reports evaluating the outcome of glaucoma filtering surgery with adjunctive MMC in glaucoma following congenital cataract surgery. With the exception of the study reported by Azuara-Blanco et $a l^{18}$ the success rate varied from $50 \%$ to $85 \% .^{3,17-22}$ The success rate of the present series is comparable to that reported by Walton, ${ }^{22}$ Asrani and Wilensky, ${ }^{3}$ Wallace et $a l^{21}$ and Beck et al. ${ }^{17}$ According to Wallace et $a l^{21}$ trabeculectomy with MMC is the most effective treatment in aphakic glaucoma following congenital cataract surgery. In sharp contrast, Azuara-Blanco et $a l^{18}$ had a poorer outcome and they were forced to comment that an alternative approach to aphakic childhood glaucoma may be necessary. Sidoti et al ${ }^{20}$ also suggested that other therapeutic approaches should be explored such as aqueous drainage implants because of the lack of effectiveness of trabeculecotmy with MMC in many cases and the potential for complications even when the successful control of IOP is achieved.

The role of glaucoma drainage implant surgery as the alternative management of refractory glaucoma following congenital cataract surgery deserves mention. The long-term bleb-related complications and the potential risk of chemotherapeutic exposure are avoided with the use of drainage implants. ${ }^{35}$ Encouraging reports obtained with the Molteno implants in young adults have led several investigators to the application of various other glaucoma drainage devices in children and young adults with various refractory glaucomas. ${ }^{36-43}$ Molteno et $a l^{36}$ and Billson et $a l^{37}$ reported success rates of 87 and 95\%, respectively. Recently, Baervelat and Ahmed glaucoma implants have been used to treat refractory glaucoma in young adults and paediatric patients, achieving success rates of 86 and $85 \%$, respectively. ${ }^{41,42}$ Molteno et $\mathrm{al}^{36}$ reported success (IOP $<20 \mathrm{mmHg}$ without any antiglaucoma medication, with a Molteno implant in 19 of 21 eyes with congenital cataracts). Billson et al ${ }^{37}$ achieved IOP control ( $<21 \mathrm{mmHg}$ without medication) in 8 of 11 eyes with childhood aphakic glaucoma after a two-stage Molteno implant with a follow-up of 1-7 years. Contradictory reports have also been published in the recent literature. Wallace et $a l^{21}$ implanted nine Molteno implants in patients with aphakia. Although six of the nine procedures resulted in IOP control at 6 months, only three maintained IOP control for 12 months after surgery. Coleman et $a l^{43}$ reported cumulative probability of success as 80 and $60 \%$ at 12 and 24 months, respectively, while Nesher et $a l^{39}$ reported a success rate of $59 \%$.

In general, the success rates of glaucoma drainage devices in refractory paediatric glaucoma are variable and also have a variable rate of complications. ${ }^{36-43}$ The comparison of the results of these studies with the present study is invalid in view of the differences in age groups included and racial variations. However, glaucoma drainage implant seems to be an interesting alternative in this refractory glaucoma. Only a prospective randomized clinical trial comparing the two treatment modalities will identify convincingly the superior surgical option for these challenging patients. Drainage implants may be a better alternative to trabeculectomy with MMC for aphakic patients who are contact lens dependants, and who may be at greater risk for late-onset bleb-related infection and endophthalmitis after surgery. ${ }^{44}$

Table 4 Reported series on trabeculectomy with or without mitomycin-C in paediatric aphakic glaucoma

\begin{tabular}{|c|c|c|c|c|c|c|}
\hline Author & $\begin{array}{c}\text { Year of } \\
\text { publication }\end{array}$ & $\begin{array}{l}\text { No of eyes } \\
\text { glaucoma }\end{array}$ & Lens status & Procedure & Success criteria & Success $(\%)$ \\
\hline Walton $^{22}$ & 1995 & 14 eyes & Aphakic & Trab.+MMC & $?$ & 64 \\
\hline $\begin{array}{l}\text { Asrani and } \\
\text { Wilensky }\end{array}$ & 1995 & 12 eyes & Aphakic & $\begin{array}{l}\text { Trab. } 5 \text { eyes } \\
\text { Trab.+MMC } 7 \text { eyes }\end{array}$ & $\mathrm{IOP}<22 \mathrm{mmHg}$ & 85 \\
\hline Wallace $e t a l^{21}$ & 1998 & 13 eyes & Aphakic & $\begin{array}{l}\text { Trab.+MMC } 4 \mathrm{~min} \text {, } \\
0.2 \text { or } 0.4 \mathrm{mg} / \mathrm{ml}\end{array}$ & $\begin{array}{l}\text { IOP }<26 \mathrm{mmHg} \text { or } \\
\mathrm{IOP}<21 \mathrm{mmHg} \\
\text { with medication }\end{array}$ & 61 \\
\hline Beck et $a l^{17}$ & 1998 & 9 eyes & Aphakic & $\begin{array}{l}\text { Trab.+MMC } 0.25 \\
\text { or } 0.5 \mathrm{mg} / \mathrm{ml} \text { for } 5 \mathrm{~min}\end{array}$ & $\begin{array}{l}\text { IOP }<22 \mathrm{mmHg} \text { with } \\
\text { or without medication }\end{array}$ & 78 \\
\hline Azuora-Blanco et $a l^{18}$ & 1999 & 8 eyes & Aphakic & $\begin{array}{l}\text { Trab.+MMC } 0.4 \mathrm{mg} / \mathrm{ml} \\
1-5 \mathrm{~min}\end{array}$ & $\begin{array}{l}\mathrm{IOP}<21 \mathrm{mmHg} \text { without } \\
\text { medication }\end{array}$ & 0 \\
\hline Freedman et al $l^{19}$ & 1999 & 4 eyes & Aphakic & $\begin{array}{l}\text { Trab.+MMC } 0.4 \mathrm{mg} / \mathrm{ml} \\
\text { for } 3-5 \mathrm{~min}\end{array}$ & $\begin{array}{l}\text { IOP } 4-16 \mathrm{mmHg} \text { with } \\
\text { medication }\end{array}$ & 50 \\
\hline Sidoti et $a l^{20}$ & 2000 & 3 eyes & Aphakic & $\begin{array}{l}\text { Trab.+MMC } 0.5 \mathrm{mg} / \mathrm{ml} \\
\text { for } 1.5-8 \mathrm{~min}\end{array}$ & $\begin{array}{l}\text { IOP } 5-21 \mathrm{mmHg} \text { with } \\
\text { medication }\end{array}$ & 66.6 \\
\hline Mandal et al & $\begin{array}{l}2002 \\
\text { Present } \\
\text { study }\end{array}$ & 23 eyes & $\begin{array}{c}\text { Aphakic } 21 \text { eyes } \\
\text { Pseudophakia } \\
2 \text { eyes }\end{array}$ & $\begin{array}{l}\text { Trab.+MMC } 0.4 \mathrm{mg} / \mathrm{ml} \\
\text { for } 2-3 \mathrm{~min}\end{array}$ & $\begin{array}{l}\text { IOP } 6-21 \mathrm{mmHg} \\
\text { without medication } \\
\text { with medication }\end{array}$ & $\begin{array}{l}\text { 36.8, Additional }{ }^{*} \\
21.1\end{array}$ \\
\hline
\end{tabular}

*Additional=with medication. 
Bleb-related infection is a serious complication of trabeculectomy with adjunctive chemotherapy and its incidence appears to have increased in recent years. ${ }^{15,17,20,21,45-48}$ Susanna et al ${ }^{15}$ reported one case in 79 cases $(1.26 \%)$ and Wallace et $a^{21}$ noted one case in 16 eyes $(6 \%)$. Beck et al ${ }^{17}$ noted late-onset endophthalmitis in five eyes of five patients $(8 \%)$ at $18-48$ months postoperatively; however, four of the five eyes had excellent outcome with continued IOP control. In the recent report by Sidoti et $a l^{20}$ five patients (17\%) had BRI at a mean follow-up of 27.9 months. Of these, two (7\%) experienced endophthalmitis with one eye becoming phthisical and the other three patients (10\%) experienced blebitis. In our own series, two eyes of a patient had BRI on separate occasions, which was successfully treated but ultimately developed choroidal detachment and hypotony that was refractory to treatment and led to severe diminution of vision. The long life expectancy in these patients as well as huge thin-walled avascular bleb coupled with difficulty in maintaining proper hygiene in children are responsible for the high rate of intraocular infection. Several studies ${ }^{46,49}$ have reported a higher frequency of endophthalmitis with the use of antimetabolites with trabeculectomy in the inferior hemisphere, so it is advisable to avoid such locations.

Considering the higher incidence of BRI in their series over an extended follow-up interval, Sidoti et $a l^{20}$ have suggested caution in using MMC as an adjunct chemotherapy in paediatric trabeculectomy. They suggested that when MMC is used as adjunct chemotherapy to trabeculectomy in children, a lower dosage (concentration, time of exposure, or both) should be considered. Agarwal et $\mathrm{al}^{16}$ reported that $0.2 \mathrm{mg} / \mathrm{ml}$ of mitomycin for $4 \mathrm{~min}$ is as effective as $0.4 \mathrm{mg} / \mathrm{ml}$ concentration in high-risk cases of congenital glaucoma, but with a lower incidence of complications and thinwalled blebs.

It is of interest that there were more surgical failures with a higher dosage of MMC in uncomplicated congenital glaucoma as reported by Mullaney et al. ${ }^{50}$ The reason for this is not clear. Megevand et $a l^{51}$ found no difference in the final IOP while using MMC with exposure time $2 \mathrm{~min}$ vs $5 \mathrm{~min}$. Stone et al $\mathrm{l}^{52}$ found similar results and the exposure time of MMC $(0.3 \mathrm{mg} / \mathrm{ml})$ ranged from 1 to $5 \mathrm{~min}$. Jampel ${ }^{53}$ suggested that the largest effect of MMC took place during the first minute of drug exposure. Based on the available reports in the literature, it is advisable to use lower concentration and shorter exposure time when adjunctive MMC with trabeculectomy is planned in paediatric patients.

A less potent chemotherapeutic agent such as 5-FU may be used in refractory paediatric glaucoma. There is a little doubt that MMC carries greater risk than does postoperative 5-FU. Zalish et $a l^{54}$ reported good success with postoperative 5-FU in congenital and infantile glaucoma. The primary disadvantage of conventional 5-FU treatment is the need for multiple postoperative visits to receive the subconjunctival injections. Good outcomes with intraoperative sponge 5 -FU in adults have been reported by several investigators. ${ }^{55-58}$ To our knowledge, there is no published report on the results of intraoperative use of sponge 5-FU in refractory glaucoma following congenital cataract surgery. We think that trabeculectomy with intraoperative sponge 5-FU with a short course of postoperative subconjunctival supplementation (if required) may be a safer alternative in this type of refractory glaucoma. A prospective randomized clinical trial comparing intraoperative MMC vs 5-FU in the carefully selected comparable group of patient population seems warranted; however, it is probably not feasible, as the patient numbers are small.

To avoid MMC-related complications, and adjunctive chemotherapy in paediatric glaucoma patients, we performed trabeculectomy with tenonectomy in nine patients with application of loose 10-0 nylon sutures or a single apical suture for closure of the superficial scleral flap. This approach was followed in view of the thinwalled avascular blebs following adjunctive antifibrotic therapy, which are prone to infections as documented in the present study as well as several other published studies. Although, the success rate of trabeculectomy with or without MMC is the same, a large number of cases and longer duration of follow-up is required to identify the superior surgical option in this situation. The bleb appearance of the patients who did not receive MMC was satisfactory and not prone to blebitis or endophthalmitis compared with the patients who received MMC intraoperatively.

The results of the present study need to be interpreted with caution. The limitations of this study include its nonrandomized, retrospective design, the wide variation in the age groups included, and arbitrary criteria for use of MMC. In addition, our series is relatively small to be able to have the power to detect differences in the outcome of trabeculectomy with or without MMC.

In conclusion, the management of glaucoma following congenital cataract surgery is challenging. Young age, subconjunctival scarring, prior surgery and aphakia or pseudophakia are significant risk factors for failure. The present study achieved a poor success rate of trabeculectomy in a small series of aphakic Asian Indian patients, even with the use of MMC. The possibility of bleb-related sequelae and complications should be discussed with the patients or parents, and children with filtering blebs who develop red eyes should be promptly evaluated. Periodic follow-up is mandatory for life. 


\section{Acknowledgement}

This study was supported in part by the Hyderabad Eye Research Foundation, LV Prasad Eye Institute, Hyderabad, India.

The authors have no proprietary interest in any of the materials or techniques used in this study.

\section{References}

1 Lambert SR, Drack AV. Infantile cataracts. Surv Ophthalmol 1996; 40: 427-458.

2 Francois J. Late results of congenital cataract surgery. Ophthalmology 1979; 86: 1586-1598.

3 Asrani SG, Wilensky JT. Glaucoma after congenital cataract surgery. Ophthalmology 1995; 102: 863-867.

4 Chrousos GA, Parks M, O'Neill JF. Incidence of chronic glaucoma, retinal detachment and secondary membrane surgery in pediatric aphakic patients. Ophthalmology 1984; 91: $1238-1241$.

5 Keech RV, Tongue AC, Scott WE. Complications after surgery for congenital and 1 infantile cataracts. Am J Ophthalmol 1989; 108: 136-141.

6 Simon JW, Mehta N, Simmons ST et al. Glaucoma after pediatric lensectomy/vitrectomy. Ophthalmology 1991; 98: 670-674.

7 Robb RM, Petersen RA. Outcome of treatment for bilateral congenital cataracts. Trans Am Ophthalmol Soc 1992; 90: 183-200.

8 Mills MD, Robb RM. Glaucoma following childhood cataract surgery. J Pediatr Ophthalmol Strabismus 1994; 31: 355-360.

9 Beauchamp GR, Parks MM. Filtering surgery in children: barriers to success. Ophthalmology 1979; 86: 170-180.

10 Cadera W, Pachtman MA, Cantor LB et al. Filtering surgery in childhood glaucoma. Ophthalmic Surg Lasers 1984; 15: 319-322.

11 Levene RZ. Glaucoma filtering surgery: factors that determine pressure control. Ophthalmic Surg Lasers 1984; 15: 475-483.

12 Maumenee AK. External filtering operations for glaucoma: the mechanism of function and failure. Trans Am Ophthalmol Soc 1960; 58: 319-328.

13 Mandal AK, Walton DS, John T, Jayagandhan A. Mitomycin C-augmented trabeculectomy in refractory congenital glaucoma. Ophthalmology 1997; 104: 996-1001.

14 Mandal AK, Prasad K, Naduvilath TJ. Surgical results and complications of mitomycin C-augmented trabeculectomy in refractory developmental glaucoma. Ophthalmic Surg Lasers 1999; 30: 473-480.

15 Susanna R Jr, Oltrogge EW, Carani JCE, Nicolela MT. Mitomycin as adjunct chemotherapy with trabeculectomy in congenital and developmental glaucoma. J Glaucoma 1995; 4: 151-157.

16 Agarwal HC, Sood NN, Sihota R, Sanga L, Honavar SG. Mitomycin-C in congenital glaucoma. Ophthalmic Surg Lasers 1997; 28: 979-985.

17 Beck AD, Wilson WR, Lynch G, Lynn MJ, Noe R. Trabeculectomy with adjunctive mitomycin-C use during pediatric glaucoma surgery. Ophthalmology 1998; 126: 648-657.
18 Azuara-Blanco A, Wilson RP, Spaeth GL, Schmidt CM, Augsburger J. Filtration procedures supplemented with mitomycin $\mathrm{C}$ in the management of childhood glaucoma. $\mathrm{Br}$ J Ophthalmol 1999; 83: 151-156.

19 Freedman SF, McCormick, Cox TA. Mitomycin Caugmented trabeculectomy with postoperative wound modulation in pediatric glaucoma. J AAPOS 1999; 3: 117-124.

20 Sidoti PA, Belmonte SJ, Liebmann JM, Ritch R. Trabeculectomy with mitomycin-C in the treatment of pediatric glaucomas. Ophthalmology 2000; 107: 422-429.

21 Wallace DK, Plager DA, Snyder SK, Raiesdana A, Halveston EM, Ellis FD. Surgical results of secondary glaucomas in childhood. Ophthalmology 1998; 105: 101-111.

22 Walton DS. Pediatric aphakic glaucoma. A study of 65 patients. Trans Am Ophthalmol Soc 1995; 93: 403-413.

23 Phelps CD, Arafat NI. Open angle glaucoma following surgery for congenital cataracts. Arch Ophthalmol 1977; 95: 1985-1987.

24 Asrani S, Freedman S, Hasselblad V. Does primary intraocular lens implantation prevent 'aphakic' glaucoma in children? J AAPOS 1999; 3: 33-39.

25 Heuer DK, Gressel MG, Parrish II RK, Anderson DR, Hodapp E, Palmberg PF. Trabeculectomy in aphakic eyes. Ophthalmology 1984; 91: 1045:-1051.

26 Tomey KF, Traverso CE. The glaucomas in aphakia and pseudophakia. Surv Ophthalmol 1991; 36: 79-112.

27 The fluorouracil filtering surgery study group. Fluorouracil filtering surgery study one year follow-up. Am J Ophthalmol 1989; 108: 625-635.

28 Whiteside-Michel J, Liebmann JM, Ritch R. Initial 5 -fluorouracil trabeculectomy in young patients. Ophthalmology 1992; 99: 7-13.

29 Chen C-W. Enhanced intraocular pressure controlling effectiveness of trabeculectomy by local application of Mitomycin C. Trans Asia-Pacific Acad Ophthalmol 1983; 9: 172-177.

30 Palmer SS. Mitomycin as adjunct chemotherapy with trabeculectomy. Ophthalmology 1991; 98: 317-321.

31 Kitazawa Y, Kawase K, Matsushita H, Minobe M. Trabeculectomy with mitomycin. A comparative study with fluorouracil. Arch Ophthalmol 1991; 109: 16931698.

32 Skuta GL, Beeson CC, Higginbotham EJ, Lichter PR, Musch DC, Bergstrom TJ et al. Intraoperative mitomycin versus postoperative 5- fluorouracil in high risk glaucoma filtering surgery. Ophthalmology 1992; 99: 438-444.

33 Katz GJ, Higginbotham EJ, Lichter PR, Skuta GL, Musch $\mathrm{DC}$, Bergstrom TJ et al. Mitomycin C versus 5-fluorouracil in high-risk glaucoma filtering surgery: extended follow-up. Ophthalmology 1995; 102: 1263-1269.

34 Khaw PT, Sherwood MB, Mackay SL, Rossi MJ, Schultz G. Five-minute treatments with fluorouracil, floxuridine, and mitomycin have long-term effects on human Tenon's capsule fibroblasts. Arch Ophthalmol 1992; 110: 1150-1154.

35 Freedman SF, (In discussion) Mandal AK, Walton DS, John $\mathrm{T}$, Jayagandhan A. Mitomycin C-augmented trabeculectomy in refractory congenital glaucoma. Ophthalmology 1997; 104: 1002-1003.

36 Molteno ACB, Ancker E, Biljon GV. Surgical technique for advanced juvenile glaucoma. Arch Ophthalmol 1984; 102: $51-57$. 
37 Billson F, Thomas R, Alward W. The use of two-stage Molteno implants in developmental glaucoma. J Pediatr Ophthalmol Strabismus 1989; 26: 3-8.

38 Munoz M, Tomey KF, Traverson C, Day SH, Senft SH. Clinical experience with the Molteno implant in advanced infantile glaucoma. J Pediatr Ophthalmol Strabismus 1991; 28: 68-72.

39 Nesher R, Sherwood MB, Kass MA, Hines JL, Kolker AE. Molteno implants in children. J Glaucoma 1992; 1: 228-232.

40 Netland PA, Walton DS. Glaucoma implants in pediatric patients. Ophthalmic Surg 1993; 24: 723-729.

41 Hill RA, Heuer DK, Baerveldt G, Minckler DS, Martone JF. Molteno implantation for glaucoma in young patients. Ophthalmology 1991; 98: 1042-1046.

42 Fellenbaum PS, Sidoti PA, Heuer DK, Minckler DS, Baerveldt G, Lee PP et al. Experience with the Baerveldt implant in young patients with complicated glaucomas. J Glaucoma 1995; 4: 91-97.

43 Coleman AL, Smyth RJ, Wilson MR, Tam M. Initial clinical experience with the Ahmed glaucoma value implant in pediatric patients. Arch Ophthalmol 1997; 115: 186-191.

44 Bellows AR, McColley JP. Endophthalmitis in aphakic patients with implanted filtering blebs wearing contact lenses. Ophthalmology 1981; 88: 839-843.

45 Greenfield DS, Suner IJ, Miller MP, Kangas TA, Palmberg PF, Flynn HW Jr. Endophthalmitis after filtering surgery with mitomycin. Arch Ophthalmol 1996; 114: 943-949.

46 Higginbotham EJ, Stevens RK, Musch DC, Karp KO, Lichter PR, Bergstrom TJ, Skuta GL. Bleb-related endophthalmitis after trabeculectomy with mitomycin-C. Ophthalmology 1996; 103: 650-656.

47 Waheed S, Ritterband DC, Greenfield DS, Liebmann JM, Sidoti PA, Ritch R. Bleb-related ocular infection in children after trabeculectomy with mitomycin-C. Ophthalmology 1997; 104: 2117-2120.

48 Sidoti PA, Lopez PF, Michon J, Heuer DK. Delayed-onset pneumococcal endophthalmitis after mitomycin-C trabeculectomy: association with cryptic nasolacrimal obstruction. J Glaucoma 1995; 4: 11-15.

49 Wolner B, Liebmann JM, Sassani JW, Ritch R, Speaker M, Marmor M. Late bleb related endophthalmitis after trabeculectomy with 5-fluorouracil. Ophthalmology 1991; 98: 1053-1060.

50 Mullaney PB, Selleck C, Al-Awad A, Al-Mesfer S, Zwaan J. Combined trabeculotomy and trabeculectomy as an initial procedure in uncomplicated congenital glaucoma. Arch Ophthalmol 1999; 117: 457-460.

51 Megevand GS, Salmon JF, Scholtz RP, Murray ADN. The effect of reducing the exposure time of mitomycin C in glaucoma filtering surgery. Ophthalmology 1995; 102: 84-90.

52 Stone RT, Herndon LW, Allingham RR, Schields MB. Results of trabeculectomy with $0.3 \mathrm{mg} / \mathrm{ml}$ mitomycin C titrating exposure times based on risk factors for failure. J Glaucoma 1998; 7: 39-44.

53 Jampel HD. Effect of brief exposure to mitomycin-C on viability and proliferation of cultured human Tenon's capsule fibroblasts. Ophthalmology 1992; 99: 14-18.

54 Zalish M, Leiba H, Oliver M. Subconjunctival injection of 5-fluorouracil following trabeculectomy for congenital and infantile glaucoma. Ophthalmic Surg 1992; 23: 203-205.

55 Mora JS, Nguyen N, Iwach AG, Gaffney MM, Hetherington J Jr, Hoskins HD Jr. et al. Trabeculectomy with intraoperative sponge 5-fluorouracil. Ophthalmology 1996; 103: 963-970.

56 Smith MF, Sherwood MB, Doyle JW, Khaw PT. Results of intraopeative 5-fluorouracil supplementation on trabeculectomy for open angle glaucoma. Am J Ophthalmol 1992; 114: 737-741.

57 Dietze PJ, Feldman RM, Gross RL. Intraoperative application of 5-fluorouracil during trabeculectomy. Ophthalmic Surg 1992; 23: 662-665.

58 Cunliffe LA, Longstaff S. Intraoperative use of 5fluorouracil in glaucoma filtering surgery. Acta Ophthalmol (Copenh) 1993; 71: 739-743. 